\title{
Kernos
}

Revue internationale et pluridisciplinaire de religion grecque antique

$31 \mid 2018$

Varia

\section{Thésée et l'imaginaire athénien. Légende et culte en Grèce antique}

Vinciane Pirenne-Delforge

\section{OpenEdition}

Journals

Édition électronique

URL : http://journals.openedition.org/kernos/3033

DOI : 10.4000/kernos.3033

ISSN : 2034-7871

Éditeur

Centre international d'étude de la religion grecque antique

Édition imprimée

Date de publication : 1 décembre 2018

Pagination : 343-344

ISBN : 978-2-87562-055-2

ISSN : 0776-3824

Référence électronique

Vinciane Pirenne-Delforge, "Thésée et l'imaginaire athénien. Légende et culte en Grèce antique », Kernos [En ligne], 31 | 2018, mis en ligne le 01 octobre 2018, consulté le 25 février 2021. URL : http:// journals.openedition.org/kernos/3033; DOI : https://doi.org/10.4000/kernos.3033

Ce document a été généré automatiquement le 25 février 2021.

Kernos 


\section{Thésée et l'imaginaire athénien. Légende et culte en Grèce antique}

Vinciane Pirenne-Delforge 


\section{RÉFÉRENCE}

Claude CALAME, Thésée et l'imaginaire athénien. Légende et culte en Grèce antique, Paris, La

Découverte, $2018^{3}$ [1990]. 1 vol. $14 \times 22,5$ cm, 509 p. ISBN : 978-2-7071-9527-2.

Dans le sixième numéro de Kernos paru en 1993 (p. 385-388), j'ai eu l'occasion de rédiger le compte rendu de la $1^{\text {re }}$ édition du livre de Claude Calame publiée en 1990. Il a connu une $2^{\mathrm{e}}$ édition en 1996, sur laquelle est fondée cette réimpression anastatique augmentée d'une postface de l'A. Les notes s'inscrivent donc toujours à la fin de chaque chapitre, mais un index avait été heureusement ajouté de la $1^{\text {re }}$ à la $2^{\mathrm{e}}$ édition. C'étaient les critiques formelles que j'avais adressées au livre à l'époque. Quant au fond, cet ouvrage reste un passage obligé pour toute étude de la figure de Thésée, mais aussi pour toute réflexion sur les relations entre les catégories modernes de «mythe » et de « rite ». Près de trente ans plus tard, l'approche narratologique structurale adoptée par l'A. reste féconde et les trois parties du livre correspondent, comme il est rappelé p. 491, «à la tripartition désormais classique de la linguistique générale: syntaxe, sémantique, pragmatique ", la "pragmatique " étant vue de manière ample en tant qu'inscription de la figure héroïque dans l'histoire athénienne du v siècle. La rigueur méthodologique de l'A. - une fois justifié le choix de suivre le fil du récit de la Vie de Thésée de Plutarque - reste un modèle du genre et les nuances apportées à l'application mécanique de la grille de lecture "initiatique " à la geste de Thésée sont toujours de rigueur. Dans la dernière partie de la postface, l'A. fait utilement le point sur la bibliographie concernant Thésée parue depuis l'édition de 1996, et renvoie aussi à quelques-unes de ses propres études qui ont approfondi la critique desdits " rites de passage » et, notamment, la question de l'homophilie masculine.

\section{AUTEURS}

\section{VINCIANE PIRENNE-DELFORGE}

Collège de France - Université de Liège 